\title{
AS RELAÇÕES DA NEUROLINGUÍSTICA DISCURSIVA COM OS FAMILIARES DAS CRIANÇAS EM PROCESSO DE APRENDIZADO DE ESCRITA E LEITURA
}

\author{
MONICA CARON ${ }^{1}$ \\ (UFSCAR)
}

\begin{abstract}
RESUMO: A proposta do artigo é mostrar a relação da área da Neurolinguística Discursiva (ND) inaugurada por Coudry (1986) com os familiares de crianças acompanhadas no Centro de Convivência de Linguagem (CCazinho/IEL-UNICAMP). Retrata uma importante e atual questão relacionando duas instituições em transformação: a Família e a Escola. A reflexão sobre essa relação é sustentada teoricamente por autores relevantes para a ND, como Vygotsky, Luria e Agamben. $\mathrm{O}$ artigo dá visibilidade a aspectos complexos da relação Escola e Família explicitando, por um lado, a diversidade de ordenações familiares, as desigualdades culturais e materiais de grande parte das famílias e, de outro, a ineficiência da escola em praticar uma gestão de aplicação de recursos tendo como finalidade o processo de aprendizagem de seus alunos, o que acaba por culminar no fracasso escolar. Defende que acontecimentos implicados na construção de parceria entre as duas instituições em benefício da criança/aluno, poderiam interferir positivamente nas proposições de Políticas Públicas Educacionais.
\end{abstract}

Palavras-chave: escola; família; políticas públicas; neurolinguística discursiva.

ABSTRACT: This work is to show the relationship between Discursive Neurolinguistics Area (ND) introduced by Coudry (1986) and relatives of children who are attended by the Centro de Convivência em Linguagens (CCazinho/IEL-UNICAMP). Currently, it is an important issue to connect two institutions in transformation processes: Family and School. This relationship has theoretically supported by Vygotsky, Luria and Agamben, relevant to ND. This work is to make visible the complex aspects of the relationship between Family and School, to explicitly explain the diversity of family ordinations, and the families' cultural and material inequalities. Additionally, it shows the school's inefficiency in practicing the application of resources management, having the students' learning as a goal, which leads to failure of the school. The work suggests that the partnership between the two institutions benefit the children/students, and need to be considered in Educational Public Policies.

Keywords: school; family; public policies; discursive neurolinguistics.

${ }^{1}$ monica.caron@gmail.com 


\section{PRIMEIRAS PALAVRAS}

Este texto é fruto de uma pesquisa ${ }^{2}$ que teve como objetivo reunir os responsáveis pelas crianças acompanhadas no $\mathrm{CCazinho}^{3}$ criando a oportunidade de apoiar os familiares adultos, coletivamente, a desenvolverem uma reflexão sobre os processos de leitura e escrita de suas crianças, a presença ou ausência da escrita em suas residências e nas dinâmicas familiares. A pesquisa foi desenvolvida entre Março de 2011 e Dezembro de 2013 e foi conduzida a partir de encontros com os pais, mães e/ou responsáveis pelas crianças, realizados em horários concomitantes aos que as crianças eram coletivamente atendidas pelos cuidadores - numa equipe de alunos da universidade orientada pela Profa. Dra. Maria Irma Hadler Coudry. Na sequência dessas atividades todos lanchavam e as crianças eram individualmente atendidas. Os encontros com os adultos (pais, mães, avós ou responsáveis pelas crianças) duravam 2 horas, semanalmente, e foram sistematicamente desenvolvidos, nos períodos letivos, no prazo de dois anos. ${ }^{4}$

\section{PANORAMA DO GRUPO DE FAMILIARES E DOS TRABALHOS}

A fim de dar um panorama das famílias atendidas, apresenta-se o Quadro 1, no qual se pode observar características gerais dos diferentes casos.

Quadro 1: Dados gerais dos familiares ${ }^{5}$

\begin{tabular}{|l|l|l|}
\hline $\begin{array}{c}\text { Mãe/ Pai/ Responsável } \\
\text { (eis)/Atividades } \\
\text { Profissionais }\end{array}$ & \multicolumn{1}{|c|}{ Filhos (as) } & \multicolumn{1}{c|}{ Singularidades } \\
\hline $\begin{array}{l}\text { S (45a) (Organizadora de } \\
\text { Eventos) }\end{array}$ & AR (9a) & $\begin{array}{l}\text { Pai de AR é distante/ausente } \\
\text { no cuidado, tem arma de fogo } \\
\text { em casa e histórico de uso } \\
\text { de drogas; S é mãe solteira } \\
\text { e foi noiva de um homem } \\
\text { por 8 anos, de quem cuidou } \\
\text { durante 5 anos em tratamento } \\
\text { de câncer, que o levou a } \\
\text { óbito; AR fez tratamento para } \\
\text { epilepsia }\end{array}$ \\
\hline C (Contadora) & $\begin{array}{l}\text { P (sem registro de idade, } \\
\text { caçula; tem 2 irmãs) }\end{array}$ & $\begin{array}{l}\text { P apresenta a síndrome do X } \\
\text { frágil }\end{array}$ \\
\hline
\end{tabular}

${ }^{2}$ Realizada em nível de pós-doutoramento, no Departamento de Linguística do IEL/UNICAMP.

${ }^{3} \mathrm{O}$ CCazinho foi idealizado pela Profa. Dra. Maria Irma Hadler Coudry junto a outros colegas do IEL (Scarpa, Mayrink-Sabinson, Possenti, Abaurre) e trabalha desde 1985 com questões relacionadas a avaliação e diagnósticos de aprendizado de leitura e escrita.

${ }^{4}$ No decorrer da pesquisa, contei com a colaboração da Dra. Sônia Bordin, linguista e fonoaudióloga.

${ }^{5}$ Alguns dados não foram encontrados nos prontuários e registros dos envolvidos: pais, mães e responsáveis (cujas presenças alternaram, em alguns casos) e crianças. 


\begin{tabular}{|c|c|c|}
\hline $\begin{array}{c}\text { Mãe/ Pai/ Responsável } \\
\text { (eis)/Atividades } \\
\text { Profissionais }\end{array}$ & Filhos (as) & Singularidades \\
\hline S (Cozinheira) & $\begin{array}{l}\text { L (13a); tem dois irmãos: } \\
\text { G (16a) e E (12a) }\end{array}$ & $\begin{array}{l}\text { L cursava a } 6^{\mathrm{a}} \text { série do Ensino } \\
\text { Fundamental }\end{array}$ \\
\hline B (Dona de casa) & $\begin{array}{l}\text { M(13a); tem dois irmãos, } \\
\text { irmão de 21a e irmã de } \\
\text { 16a }\end{array}$ & $\begin{array}{l}\text { M foi diagnosticada com } \\
\text { dislexia } \\
\mathrm{B} \text {, analfabeta, recusou-se a } \\
\text { dar ritalina (indicada pelo } \\
\text { médico) para } \mathrm{M}\end{array}$ \\
\hline M (35a) (Dona de casa) & $\begin{array}{l}\text { P (10a); tem dois irmãos } \\
\text { com doenças mentais, } \\
\text { severas limitações e } \\
\text { inúmeras necessidades } \\
\text { especiais }\end{array}$ & $\begin{array}{l}\text { Pai de } \mathrm{P} \text { ausente, mudou-se } \\
\text { para o Japão } \\
\text { Quem sustenta a família é o } \\
\text { pai de } \mathrm{M} \text {, avô materno de P }\end{array}$ \\
\hline $\mathrm{S}$ (Dona de casa)/ A & $\begin{array}{l}\text { G (11a); tem um irmão } \\
\text { de } 13 a\end{array}$ & $\begin{array}{l}\text { G frequentou o CCazinho } \\
\text { desde os } 7 \text { anos } \\
\text { G teve menarca em } 2013 \\
\text { Pais de G são separados } \\
\text { S tem ensino médio, de } \\
\text { Sumaré }\end{array}$ \\
\hline $\begin{array}{l}\text { S (Auxiliar de Enfermagem) } \\
\text { histórico de anorexia/ S (Tia) } \\
\text { Monitora Infantil/ A (Avô) } \\
\text { Pedreiro }\end{array}$ & $\begin{array}{l}\text { I (8a); tem dois irmãos, } \\
\text { T de } 7 \text { a e LA de } 5 a \\
\text { Cada filho é de um pai }\end{array}$ & $\begin{array}{l}\text { I foi diagnosticado com } \\
\text { transtorno bipolar } \\
\text { S (mãe) e S (tia) passaram } \\
\text { por tratamento de depressão } \\
\text { e estresse durante o trabalho; } \\
\text { dizem que o pai delas } \\
\text { começou a beber aos } 6 \text { anos } \\
\text { de idade, foi agressivo, } \\
\text { batia muito nelas e era } \\
\text { extremamente anti-social }\end{array}$ \\
\hline N/M (38a) & M (11a); tem uma irmã & $\begin{array}{l}\mathrm{N} \text { (mãe) cursou até a } 8^{\text {a }} \text { série e } \\
\mathrm{M} \text { (pai) até o } 1^{\circ} \text { ano de curso } \\
\text { superior, de Valinhos } \\
\mathrm{M} \text { (criança) diagnosticada } \\
\text { disléxica, na } 4^{\mathrm{a}} \text { série, com } \\
\text { dificuldades relacionadas à } \\
\text { alimentação, recusando-se } \\
\text { a comer arroz e a mastigar } \\
\text { alimentos }\end{array}$ \\
\hline
\end{tabular}




\begin{tabular}{|c|c|c|}
\hline $\begin{array}{c}\text { Mãe/ Pai/ Responsável } \\
\text { (eis)/Atividades } \\
\text { Profissionais }\end{array}$ & Filhos (as) & Singularidades \\
\hline $\mathrm{E}$ & $S(13 a)$ & $\begin{array}{l}\text { S é vítima de bullying } \\
\text { E interrompeu o atendimento } \\
\text { por ter desenvolvido um } \\
\text { câncer }\end{array}$ \\
\hline J (Avó) & A & $\begin{array}{l}\text { Casos de alcoolismo na } \\
\text { família (marido e filho) }\end{array}$ \\
\hline $\mathrm{MC} / \mathrm{F}$ & $\mathrm{F}$ & $\begin{array}{l}\text { MC foi freira/ relata que } \mathrm{F} \\
\text { (pai) é machista e violento } \\
\mathrm{F} \text { (filho) diagnosticado com } \\
\text { miastenia gravis }\end{array}$ \\
\hline $\mathrm{D}$ & $\mathrm{B}(12 \mathrm{a})$ & $\begin{array}{l}\text { D teve graves problemas } \\
\text { auditivos durante todo o } \\
\text { desenvolvimento }\end{array}$ \\
\hline I & $\mathrm{R}(4 \mathrm{a})$ & $\begin{array}{l}\mathrm{R} \text { teve } 2 \text { AVCs, é filha do } \\
\text { marido de } \mathrm{R} \text { com a primeira } \\
\text { esposa deste } \\
\mathrm{R} \text { não fala, mas escreve }\end{array}$ \\
\hline $\mathrm{D}$ & AP & AP é filha adotiva \\
\hline $\begin{array}{l}\mathrm{V} \text { (Cabelereira) } \\
\text { Interrompeu o trabalho por } \\
\text { ter desenvolvido um câncer }\end{array}$ & $\begin{array}{l}\text { F (11 a); tem dois irmãos, } \\
\text { T de } 23 \mathrm{a} \text { e R de } 18 \mathrm{a}\end{array}$ & $\begin{array}{l}\text { V viveu com o pai de } \mathrm{F} \text { até os } \\
\text { de } 3 \text { anos da criança } \\
\text { F adora motos/motores, não } \\
\text { gosta da escola, passou } \\
\text { por cinco escolas que o } \\
\text { reprovaram, não obteve } \\
\text { atendimento no conselho } \\
\text { tutelar } \\
\text { Médico psiquiatra do posto } \\
\text { deu carbamazepina, o que } \\
\text { diminuiu agitação de F }\end{array}$ \\
\hline Z (Faxineira) & $\mathrm{L}(15 \mathrm{a})$ & \\
\hline E (Cabelereira)/I (32a) & $V(8 a)$ & $3^{a}$ série \\
\hline S & $\mathrm{R}(12 \mathrm{a})$ & $\begin{array}{l}\mathrm{S} \text { diz que } \mathrm{R} \text { ficou melhor } \\
\text { com a retirada da fluoxetina } \\
\text { indicada por médico }\end{array}$ \\
\hline
\end{tabular}




\begin{tabular}{|l|l|l|}
\hline \multicolumn{1}{|c|}{$\begin{array}{c}\text { Mãe/ Pai/ Responsável } \\
\text { (eis)/Atividades } \\
\text { Profissionais }\end{array}$} & \multicolumn{1}{|c|}{ Filhos (as) } & \multicolumn{1}{c|}{ Singularidades } \\
\hline R (11a) & $\begin{array}{l}\text { N é filha única, cuidada pela } \\
\text { avó, faz birra e manhã, queixa } \\
\text { de que "está sem limites", } \\
\text { teve menarca em 2013 } \\
\text { R diz que os pais eram muito } \\
\text { rígidos e casou-se para livrar- } \\
\text { se deles }\end{array}$ \\
\hline $\begin{array}{l}\text { AP (Atendente em escola)/ } \\
\text { T (Metalúrgico) }\end{array}$ & $\begin{array}{l}\text { V (12a); tem uma irmã C } \\
\text { de 6a }\end{array}$ & $\begin{array}{l}\text { V diagnosticado com } \\
\text { problemas de aprendizagem } \\
\text { (dificuldade de processamento) } \\
\text { desde os 6 anos; fez } \\
\text { psicoterapia; sempre estudou } \\
\text { em escolas particulares, com } \\
\text { bolsa, nas mesmas escolas } \\
\text { em que a mãe trabalhava, de } \\
\text { Jundiaí } \\
\text { 3a escola e na 6 6érie }\end{array}$ \\
\hline
\end{tabular}

Com o objetivo de ilustrar o nível de escolaridade do grupo de famílias atendido, representante de variantes não-padrão, "marcadas" e, consequentemente, passível de preconceito pela forma como se expressa, apresentam-se, a seguir, alguns registros de falas que permitem antever-lhe a classe social e especificidade no dizer: B (22 de mar. de 2011): "Ele véve num mundo que não é o nosso, não sabe que dia é hoje, não conhece dinheiro"; "expricô"; D (29 de mar. de 2011): "O pessoal daqui são diferente"; S (29 de mar. de 2011): "A imaginação deles vão"; I (24 de maio de 2011): "Qui nóis senti"; M (24 de maio de 2011): "Eles vai. Eles vorta"; J (09 de ago. de 2011): "Poligráfico" para "pornográfico"; E (15 de maio de 2012): "A escola comprimi muito os alunos daqui"; S (22 de maio de 2012): "Todo ano eu, minha mãe e o R vai"; Z (22 de maio de 2012): "Nói somo do interior, não sabe nada"; I (22 de maio de 2012): "As meninas estão quilometrando o tempo que a R leva para escrever uma linha"; sem registro de autoria (21 de ago. de 2012): "malmita" para "marmita; "estomo" para "estômago"; "figo" para "fígado"; B (11 de jun. de 2013): "M é aconselhado ponhá na academia"; A (17 de out. de 2013): "Eu di uma olhada". Para encerrar os exemplos, segue o depoimento de uma mãe, sem registro de autoria, com ocorrência em uma ocasião em que discutíamos a presença da mídia televisiva no contexto nacional, que resume a variedade no dizer que se pretende explicitar mas também a diferença entre o grupo dos profissionais que atuam no CCazinho (posto que a equipe que forma o CCazinho conta com três professores doutores, psicóloga, fonoaudióloga, estudantes das áreas de Letras, Linguística e ou de outras graduações da universidade; ou seja, têm bons níveis de escolaridade e acesso à norma culta) e o das famílias: (03 de set. de 2013) "Você não é da periferia e não conhece a realidade. A barra é pesada". 
No início dos trabalhos quisemos enfatizar para os familiares a necessidade $\mathrm{e}$ importância de terem planos para os filhos e estabelecerem vias para os realizarem. Para isso, sugerimos que pensassem na pergunta: o que queremos para nossas crianças? Desde ponto buscamos ressaltar, ao longo do trabalho, a importância do modelo oferecido pelos familiares no trato cotidiano da leitura, da escrita e dos suportes textuais. Também refletimos sobre o valor que tem a proposição de tarefas diárias com uso significativo/real da escrita, como na confecção de listas de supermercado; incentivo de realizarem pesquisas sobre temas que interessem aos filhos. Alguns familiares comentaram que o filho estava, na época, pesquisando e escrevendo um livro sobre peixes (AR) e outro que o filho (M) gostava de carros e de assistir a programas na National Geographic Channel sobre os oceanos e a Terra. Entre as atividades desenvolvidas no CCazinho teve uma com o trabalho de biografias e AJ pesquisou a vida de Ronaldinho (jogador de futebol), F a vida de Júlio César (imperador) e AR a vida da cachorra Laica (primeiro animal enviado ao espaço). A despeito desse enfoque dado pelos pesquisadores, os familiares questionavam, recorrentemente, por exemplo, como tratar problemas com álcool, drogas, sexo, relacionamentos com os filhos e os parceiros, e a natureza dos relacionamentos amorosos, com ex-companheiros, a questão dos ciúmes e da desconfiança, mas também as reuniões de pais e professores nas escolas, o desempenho escolar dos filhos, doenças graves na família, o uso de drogas na adolescência, a violência física entre familiares, casos de estupro e assassinatos de terceiros, mães que têm raiva de maridos pouco participativos, a percepção das crianças dos problemas familiares e a repercussão dos conflitos, a importância de cuidar das crianças - mas, também, de lhes dar, paulatinamente, independência, de cultivar amigos na vida, a "reza"/fé como solução para o sofrimento de outras mães, o sentimento de não gostar do filho ou de outras pessoas (em dia em que uma mãe trouxe texto baseado na teoria de Winnicott, sobre "como criar filhos saudáveis" e ser uma "mãe suficientemente boa"). ${ }^{6}$ Uma presença masculina às reuniões determinava diferentes rumos às conversas, quando comparado com os encontros com presença exclusiva de mulheres.

Pedimos às mães que trouxessem material para lermos durante as atividades; uma mãe trouxe a bíblia e indagamos, após leitura de um trecho do livro, se esse material seria o mais indicado (e se é mesmo adequado) para incentivar a leitura e o apreço por ela, pelo filho; uma mãe trouxe o texto "A bela e a fera". Nessa atividade discutimos a diferença entre "ler" e "decodificar", assunto que surgiu a partir da leitura que uma mãe fez, considerada "embolada" pelas demais. Nessa atividade, algumas mães ficaram muito constrangidas, sendo que uma delas recusou-se veementemente a ler em voz alta para o grupo, alegando desconforto e timidez. Uma delas leu o texto "A cabra e a mula". Comentouse, nessa atividade, da necessidade de colocar-se no lugar da criança. Foi feita uma leitura, por uma das responsáveis pelos trabalhos, com o intuito de "servir

${ }^{6}$ Winnicott (1896-1971), pediatria e psicanalista, estudou a relação mãe e filho e sustentou a ideia de que a saúde mental está relacionada com o desenvolvimento emocional primitivo do bebê, a pre-ocupação materna primária. 
de modelo". Lemos a história de "Narciso" e comentamos sobre a importância de gostar de si próprio. Uma mãe comentou que, apesar de sua própria mãe ser analfabeta, sabia contar histórias. Discutiu-se, durante essa atividade, sobre a noção de gênero de textos, ao falarmos de música e da importância dos jogos infantis de linguagem para o desenvolvimento das habilidades motoras e dos movimentos finos das crianças.

Uma queixa frequente na fala das mães, entre outras já apontadas, é a sobrecarga que nelas recai no que tange à responsabilidade na educação dos filhos. Os pais (a maioria deles com pouca escolarização) parecem entender que a função deles é prover alimentos e a manutenção física do lar, entendendo que os aspectos relativos à conduta, comportamento e afeto dos filhos é responsabilidade das mães, que se vêm obrigadas a dar em excesso e muitas vezes o que não têm. Esses pais também parecem negligenciar o modelo que oferecem aos filhos, sendo muitas vezes impulsivos, agressivos ou, pelo contrário, apáticos. Obviamente que, por seu turno, podem também estar se sentindo coagidos a dar o que não dispõem, pois também são resultado de uma criação recebida e esse ciclo se repetirá indefinidamente, até que um membro da família se proponha a avaliar, questionar, buscar novas formas, encontrar falhas nos modelos e modos alternativos de relacionar-se familiarmente. Não temos a fala desses pais, pois nosso grupo era predominantemente composto por mães, o que reforça nossa hipótese de que a educação e o desempenho dos filhos na escola parecem ser parte dos encargos da mãe. Há, inclusive, pais que se recusam a comparecer aos encontros, entendendo-os como desnecessários e infrutíferos. Há depoimento de mãe que confirma que o pai não dá valor para a escola e às produções escolares dos filhos e que valoriza apenas o futebol.

\section{ASPECTOS TEÓRICOS BALIZADORES}

O trabalho realizado com os familiares do CCazinho assume da teoria vygotskyana a noção de que a linguagem (oral e escrita) se constitui no jogo social em que comparecem o outro - família, escola e políticas públicas - além da própria criança; e também assume a ideia de aprendizagem como um movimento em espiral, ou seja, para se aprender o novo passa-se pelo conhecimento prévio (formado em determinado contexto histórico-cultural, competências construídas), que influencia novas aprendizagens (VYGOTSKY, 1926/2004). Cabe ressaltar que o autor constituiu-se como um dos pilares da Neurolinguística fundada por Coudry, já em sua primeira obra, em 1986, sobretudo por sua perspectiva interacionista e dialógica. Assim, o trabalho coletivo que acontece pela mediação gera a possibilidade do individual, da diferenciação, da singularização, da particularização do sentido na história do sujeito. Para Vygotsky (1987), a relação entre o pensamento e a palavra é um movimento contínuo de vai e vem do pensamento para a palavra e vice-versa, em que o significado é a união da palavra e do pensamento. De tal modo - o pensamento não é expresso por palavras; é por meio delas que ele passa a existir (VYGOTSKY, 1987, p. 109). 
Para Vygotsky (1934/1979) e Coudry (1986), apoiada ainda em Franchi (1977; 1987), a linguagem é fator desencadeante de outros processos que passam pelo corpo, como percepção, associação, memória, pensamento; portanto, entender como as famílias nos contam das crianças, e como essas crianças constituem sua auto-imagem, exige pensar como essas crianças entraram na linguagem e como isto repercute nos processos que se dão a partir da linguagem.

Dos estudos de Vygostky (1934/1987, 1926/2004), privilegia-se a ideia de que a criança (onto e filogeneticamente) interage com o mundo através de instrumentos que depois são simbolicamente representados na linguagem pelos signos. As primeiras respostas que a criança dá ao mundo são determinadas pelos processos biológicos, mas na constante mediação com adultos ou pessoas mais experientes emergem processos psicológicos mais complexos, as Funções Psicológicas Superiores (percepção, memória, linguagem e pensamento, generalização e abstração, atenção e imaginação), da combinação entre fala e inteligência prática, entre instrumento e signo.

As implicações do autor citado na prática do acompanhamento coletivo dos familiares se revelam na valorização do conhecimento prévio como indícios da inserção social dos adultos e do uso social da leitura e escrita que incidem no movimento em espiral da aprendizagem. Além disso, a importância da mediação do outro (mais capaz ou mais experiente) exercendo o papel daquele que possibilita que a criança pense sobre as hipóteses que usa para ler e escrever; para pensar a leitura e a escrita no ambiente e cotidiano familiar e, com isso, gradualmente, para que ela se torne autônoma nos processos que envolvem o ler e o escrever.

Aqui podemos destacar a pesquisa quantitativa de Menezes-Filho ${ }^{7}$ que aponta que "as variáveis que mais explicam o desempenho escolar são as características familiares e do aluno, tais como educação da mãe, cor, atraso escolar e reprovação prévia, número de livros, presença de computador em casa e trabalho fora de casa" ( $\mathrm{s} / \mathrm{p})$. Evidências diversas mostram a importância da educação nas várias dimensões econômicas e sociais e inúmeros estudos mostram que maior escolaridade implica em aumento nos salários das pessoas, além de diminuir a propensão ao crime, melhorar a saúde e diminuir a probabilidade de ficar desempregado.

Destarte, ainda que na década de 90 o Brasil tenha ampliado o acesso à educação de forma relativamente rápida, o histórico atraso educacional no país é causado pela falta de políticas educacionais apropriadas. A grande questão que se coloca é como elevar a qualidade da educação que é oferecida nas escolas públicas brasileiras mantendo no sistema as crianças mais pobres. Corroborando nossas expectativas, o autor mostra que "as variáveis do aluno e de sua família são as que têm maior impacto e poder explicativo para a proficiência escolar" (s/p). Dado ainda mais interessante encontrado é que "entre as variáveis do aluno, entre as mais importantes está a escolaridade da mãe" $(\mathrm{s} / \mathrm{p})$.

\footnotetext{
${ }^{7}$ A publicação do trabalho na internet não é datada.
} 
O que se anuncia é que o palco onde as forças motivadoras atuam para o desenvolvimento psicológico e intelectual das crianças situa-se em locais em que se desenrolam as circunstâncias históricas concretas de suas vidas, que são a força motriz das alterações no sistema das relações humanas, desenvolvidas segundo as exigências dessas mesmas circunstâncias e que exercem influência, de forma substancial, no caráter psicológico da personalidade infantil, fortemente atrelada a sentimentos de alegria, tristeza e motivação que ela encontra nesse ambiente (LEONTIEV, 1988).

Há um processo mediador entre a criança e o mundo constituído pelas relações sociais. O mundo, então constituído pela história social, apresentará através dessas relações sociais diferentes necessidades, exigências e motivos que servirão de base para a regulação do comportamento da criança e a história social passa a constituir a base para a história individual, inicialmente na formação de sentidos e não puramente de conhecimento. Esses sentidos traçam a consciência da criança, que é a matéria subjetiva composta por sensações, expressões emocionais, fenômenos sensoriais e memória. As atividades mudam de acordo com as novas exigências na relação com a realidade, plasticidade importante para a constituição da psique infantil. A gênese deste processo é constituída pelo desenvolvimento da linguagem que, necessariamente, passa por meio de outra pessoa. A partir deste ponto, criança e mundo são enraizados em um processo complexo de ligação cultural da história social com a individual (LURIA, 1988).

Trata-se de um processo dialógico em que a construção dos significados a partir da fala ou da leitura do outro em torno de um acontecimento ou de um texto ocorre pelo confronto de conceitos, em um movimento de negociação e construção do sentido. As operações com os signos, produtos do desenvolvimento social, são resultado de transformações qualitativas das operações psicológicas frente aos dinâmicos estímulos extrínsecos, obedecendo a evolução psicológica infantil como diferentes estágios de um mesmo processo sempre pautado em sua natureza histórico-cultural. O resultado final não é decorrente de um processo que provém de fora para dentro em um sentido determinante e unidirecional, mas constitutivo, transformador, baseado em conflitos e trocas.

Duas linhas operam para a ocorrência desse processo de construção de signos e diferem quanto à suas origens. A primeira linha é de origem biológica, que constitui os processos elementares e, a outra linha, é de origem sociocultural, que constitui as funções psicológicas superiores. É na relação dessas duas linhas que o desenvolvimento psicológico da criança acontece (LEONTIEV, 1988).

Bruner (1997) tem como premissa central em sua psicologia a orientação cultural. A subjetividade é elevada a um status explicativo, deixando de ser apenas um fenômeno compreendido pela psicanálise. Sua abordagem considera $o$ quê as pessoas dizem sobre seus estados mentais e assume que há uma relação entre o que as pessoas dizem e o que elas fazem. Mais importante, as ações e as palavras revelam significados interpretáveis publicamente e negociáveis pelos membros da comunidade. Cada instituição, cada família remete a significados e interpretações possíveis, já que toda ação é situada em um cenário cultural e em estados intencionais dos agentes (BRUNER, 1997). 
As crianças são envolvidas por muitas histórias que, na maioria das vezes, fogem à previsibilidade dos finais comuns e as deixam sem a certeza de como terminarão. Todo ser humano, ao longo de seu desenvolvimento, sofre um processo de construção de sua identidade pessoal e seu autoconceito pelo uso do discurso narrativo, por meio do qual transforma sua individualidade em um contexto dinâmico, composto por vários cenários e eventos que exigem constante reflexão. Nessas circunstâncias, é necessária uma revisão de significados e interpretações dos novos eventos que são acrescentados às suas vidas, revelando a importância da ação de outros personagens que a ajudem nesse processo. Uma vez diante de determinada circunstância nova, como uma doença na família, a criança já tem sua cultura moldada no ambiente familiar, sendo consequentemente uma expressão dela; por isso a compreensão de questões subjetivas, como os conceitos de uma doença, saúde e estigmas são importantes para o desenvolvimento cognitivo e afetivo da criança (QUINTANA et al., 2007).

Escolas são locais onde se dão ações educativas. Podem ser entendidas como estabelecimentos de ensino que devem possibilitar aos cidadãos, independentemente das suas diferenças e necessidades, o desenvolvimento das competências e habilidades que lhes auxiliem a explorar plenamente os seus potenciais, integrando-se ativamente à sociedade e contribuindo para a vida econômica, social e cultural do país. No tangente às diferenças entre os cidadãos, que podem ser relacionadas aos ritmos de aprendizagem, habilidades e níveis de funcionamento diversos, além de características pessoais e sociais muito variadas, a universalização da educação trouxe para a escola a riqueza e a verdade que a diferença encerra levando questões cruciais aos professores e, por vezes, muito difíceis, na gestão da sala de aula e no modo de ensinar crianças com características singulares.

Soma-se à escola a família como um dos principais agentes responsáveis pela inclusão da criança na sociedade. Ao pensarmos nas relações existentes entre as famílias e as escolas, devemos considerar as mudanças históricas que têm ocorrido nestas instituições e em seus atores; a diversidade de ordenações familiares; e as desigualdades culturais e materiais de grande parte das famílias.

Primeiro campo de socialização para a criança, na família é onde são desenvolvidos o crescimento físico, pessoal e emocional. Assim, é um sistema complexo e mutável de organização social, imerso em um contexto espaço-temporal em que coexistem diferentes padrões, estruturas e funções e, de acordo com essas interações, nela afirma-se a relação com a saúde e as doenças. Há um desequilíbrio causado pelas doenças e/ou incapacidades que faz com que os familiares sofram com diversos sentimentos, como a preocupação, o medo e a angústia face ao desafio que é conviver com uma doença e aprender a gerir e a atender as necessidades do doente e dos outros membros da família. O medo da incapacidade também é sempre presente, uma vez que uma doença pode ter o caráter permanente e de acumulação residual de incapacidades (MARTINS; FRANÇA; KIMURA, 1996). 
A política educacional, por sua vez, e seus produtos (currículos, práticas pedagógicas) são elaborados a partir de um modelo de família que, segundo Carvalho (2004), subordina a família à escola e sobrecarrega as mães, o que corrobora nossa experiência no CCazinho. Para a autora, "a relação família-escola também será variavelmente afetada pela satisfação ou insatisfação de professoras e de mães/pais, e pelo sucesso ou fracasso do/a estudante" (2004, p. 45). No entanto, famílias são categorias heterogêneas e disso decorrem as diferentes dinâmicas entre as famílias e as escolas.

Nossa experiência e as pesquisas apontam o que “(...) há muito sabemos, embora haja exceções, que o fracasso escolar atinge as crianças das famílias mais pobres das escolas públicas mais carentes" (CARVALHO, 2004, p. 46). O modelo de família que a escola e a administração pública parecem querer encontrar "é o modelo tradicional de família de classe média, que não corresponde às condições de vida da maioria das famílias pobres, trabalhadoras, e que está desaparecendo na própria classe média, com o ingresso das mulheres em ocupações remuneradas" (CARVALHO, 2004, p. 47).

Ainda que pais, mães e responsáveis desejem o sucesso escolar para as crianças, sendo parceiros/aliados dos professores e das escolas, não são todas as famílias que dispõem de condições que englobam, entre outras coisas, a valorização da escola, tempo, familiaridade com as matérias escolares e habilidades para ensinar o dever de casa e motivar interesse acadêmico. Ademais, como aponta Carvalho,

parceria supõe igualdade, e as relações escola-família são relações de poder em que as/os profissionais da educação (pesquisadoras/es, gestoras/es, especialistas, professoras/es) têm poder sobre os leigos (pais/mães). São relações também mediadas por outras relações de poder (de classe, raça/etnia e gênero) que, em princípio, ora podem favorecer as/os professoras/es, ora os pais ou mães ou responsáveis. Em todo caso, o poder dos pais/mães encontra sempre seu limite no poder da professora sobre seu filho/filha na sala de aula (afinal, pais/ mães sabem que professores/as são seres humanos, tanto quanto eles/elas, sujeitos a antipatizar, marcar, dar gelo...) (CARVALHO, 2004, p. 53).

Concordando com a autora, entende-se aqui que é necessário pensar o que se espera da dinâmica família-escola, pois mesmo reconhecendo-se a interdependência entre elas, isso não significa identidade de competência.

O significado social da infância, desenvolvido na modernidade, foi concebido diante das necessidades estabelecidas pela racionalização do homem e pela organização do capital. A modernidade, por sua vez, como proposta de Touraine (1994), sociólogo francês, traduz-se como uma época que trouxe consigo distintos problemas sociais e econômicos de interesse público (desigualdade social, pobreza, fome, desemprego, acumulação de riquezas, impactos ambientais, tensões multiculturais, etc.) que influenciam o homem e sua maneira geral de ser/viver, que desafiam as instituições políticas e pressionam em favor de estratégias de subjetivação, projetando o sujeito para o centro do palco social. Em um projeto de esforço global, para Touraine (1994), a modernidade luta contra os valores e o modo de vida tradicionais na busca de melhores condições de produção e organização social. Destarte, seu desenvolvimento gerou contrassensos e a modernização estaria se dirigindo para uma sociedade programada. 
O conceito de infância do homem, origem da experiência e da história, desenvolvido por Agamben (1978/2005), é uma tentativa de pensar os limites da linguagem em uma direção que não é trivial, do inefável, pois a infância encontra o seu lugar lógico em uma exposição da relação entre experiência e linguagem (experiência transcendental indicada no programa benjaminiano da filosofia). Para o autor, "uma das tarefas mais urgentes do pensamento contemporâneo é certamente a redefinição do conceito de transcendente em função de suas relações com a linguagem" (AGAMBEN, op. cit., p. 11).

Para o autor, a infância instaura na linguagem uma cisão entre língua e discurso "que caracteriza de modo exclusivo e fundamental a linguagem do homem” (AGAMBEN, 1978/2005, p. 63). De sua perspectiva, a partir dos estudos de Benveniste, começou-se a entrever a problemática e a importância da cisão entre língua e fala, entre semiótico (caracterizado como uma propriedade da língua que não comporta aplicações particulares) e semântico (resultado de uma atividade do locutor que coloca em ação a língua), entre sistema de signos e discurso. Nas palavras de Agamben:

somente porque existe uma infância do homem, somente porque a linguagem não se identifica com o humano e há uma diferença entre língua e discurso, entre semiótico e semântico, somente por isto existe história, somente por isto o homem é um ser histórico (AGAMBEN, 1978/2005, p. 64).

Na medida em que o homem possui uma infância, em que não é sempre já falante, só pode entrar na língua como sistema de signos transformando-a radicalmente e constituindo-a em discurso. Para Agamben, semiótico e semântico são, sobretudo, "os dois limites transcendentais que definem a infância do homem e são, simultaneamente, definidos a partir dela" (AGAMBEN, 1978/2005, p. 68).

Da diferença irredutível, que separa o plano da língua e do semiótico do plano da fala e do semântico, constitui-se a base para o questionamento radical da lógica e da metafísica; a formulação desta diferença permite à ciência da linguagem chegar "ao seu limite incontornável, além do qual não pode prosseguir sem transformar-se em filosofia” (AGAMBEN, 1978/2005, pp. 71-72), da qual resulta a oposição entre natureza e cultura, ou a dupla herança que define "o homo sapiens, endossomática e exossomática; natureza pode significar somente o patrimônio hereditário transmitido através de código genético, ao passo que cultura é o patrimônio heriditário transmitido por meio de veículos não genéticos" (AGAMBEN, op. cit.), dentre os quais o mais importante é certamente a linguagem.

A exposição à linguagem no homem é condição imprescindível para o seu aprendizado, pois o homem não é o animal que possui linguagem, mas é o animal desprovido "dela e que deve, portanto, recebê-la de fora" (AGAMBEN, 1978/2005, pp. 72-73). Para o autor 
no homem produziu-se uma separação entre a disposição para a linguagem (o estarmos prontos para a comunicação) e o processo de atualização desta virtualidade. A linguagem humana apresenta-se, portanto, cindida originalmente em uma esfera endossomática e em uma esfera exossomática, entre as quais se estabelece (pode estabelecer-se) um fenômeno de ressonância que produz a atualização. Se a exposição à herança exossomática não intervém durante uma certa fase do desenvolvimento da plasmaticidade cerebral (que, segundo Lennenberg, tem seu limite extremo no processo de lateralização cerebral, que se conclui por volta dos doze anos), a disposição para a linguagem é irreversivelmente perdida (AGAMBEN, 1978/2005, p. 73).

No sentido geral, educar não é tarefa exclusiva de pais e mães biológicos, da família ou da escola. Carvalho (2004) observa que nos processo educacionais, no passado

o cuidado dos mais jovens, a transmissão da cultura do grupo social (o ensino de modos de conhecimento, produção, relação e participação) e a preparação para os papéis adultos (na guerra, trabalho, sexualidade, família e cidadania) eram tarefas educativas assumidas por vários indivíduos, grupos e instituições (mães, pais, idosos/as, professores/as, famílias extensas, clãs, tribo, vizinhança, comunidade, igrejas e escolas) por meio de uma variedade de arranjos (CARVALHO, 2004, p. 48).

A partir da escolarização obrigatória, em fins do século XIX, a educação escolar tornou-se o modo de educação predominante nas sociedades modernas, democráticas, com uma organização específica:

currículo seriado, sistema de avaliação, níveis, diplomas, professores, professoras e outros profissionais especializados. Entretanto, como um processo multifacetado de aprendizagem e desenvolvimento humano pela experiência e participação nas várias práticas e espaços sociais ao longo de toda a vida, a educação deve ser distinguida da escolarização (CARVALHO, 2004, p. 49).

A fundação da escola moderna está relacionada ao surgimento das classes médias, ou seja, à transformação dos modos de produção econômica, pois o advento da escola de massas representou uma solução para a reprodução social e educação individual na nova ordem urbano-industrial, substituindo a família e a comunidade" (CARVALHO, 2004, pp. 50-51). Na segunda metade do século XIX, em decorrência das necessidades de expansão do trabalho feminino, deu-se o surgimento das creches (para os filhos dos trabalhadores) e da educação infantil nos jardins-da-infância (para atender os filhos das classes altas), em época de expansão e auge da indústria. Ao longo da história, como transmissão cultural, a educação distinguiu-se em popular e erudita, sendo a primeira oral e prática e a segunda letrada, formal, sinônimo de cultura, sendo esta reservada às elites e realizada nas casas, com mestres e mestras residentes ou em colégios internos.

Ao proporcionar às famílias a oportunidade de debate, de procedimentos e de entender as suas necessidades terapêuticas, bem como suas limitações, como nos propomos no CCazinho, coloca-se a família em uma posição em que ela compreende que pode participar de maneira ativa na situação, através da abertura à comunicação e ao questionamento, possibilitando até mesmo sua colaboração nas estratégias terapêuticas. A pessoa só atua em sua realidade 
quando tem consciência de sua condição e autonomia para atuar sobre ela, a partir de sua capacidade de reflexão crítica sobre si e seu contexto. Autonomia significa liberdade ou não estar sob opressão de um autoridade dominadora. O exercício da liberdade é expresso pela sua ação de escolha e assunção de sua responsabilidade (FREIRE, 1996).

Ao buscar estabelecer uma correlação entre letramento e condição social, uma pesquisa nacional, denominada Indicador de Alfabetismo Funcional (Inaf), realizada pelo Instituto Paulo Montenegro - Ação Social do Ibope e pela ONG Ação Educativa, possibilitou visualizar que o tempo de escolaridade e a condição socioeconômica são proporcionais ao desempenho do cidadão no alcance satisfatório do letramento. Por outro lado, o Índice de Desenvolvimento Humano (IDH), síntese da longevidade, educação e renda do Brasil, traduz sua situação de desigualdade social e de não cumprimento do que determina a Constituição Federal Brasileira ${ }^{8}$ (BRASIL, 1988). É saber comum que uma parcela expressiva da população brasileira não tem condições de desenvolver e amadurecer a prática leitora, o que é determinado por fatores de diferentes naturezas e complexidades, inclusive pelas políticas públicas de educação implementadas pelo Governo, entendido como proposto por Höfling, enquanto

o conjunto de programas e projetos que parte da sociedade (políticos, técnicos, organismos da sociedade civil e outros) propõe para a sociedade como um todo, configurando-se a orientação política de um determinado governo que assume e desempenha as funções de Estado por um determinado período (HÖFLING, 2001, p. 31).

As políticas públicas são responsabilidade do Estado, concebido, por sua vez, ainda de acordo com proposição de Höfling (2001), como o conjunto de instituições permanentes - como órgãos legislativos, tribunais, exército e outras que não formam um bloco monolítico necessariamente - que possibilitam a ação do governo. Se, de um lado, temos as políticas públicas, de outro temos as políticas sociais, tangentes a ações que contribuem para a proteção social, "voltadas, em princípio, para a redistribuição dos benefícios (...) visando a diminuição das desigualdades estruturais produzidas pelo desenvolvimento socioeconômico" (HÖFLING, 2001, p. 31).

Nesses termos, apenas quando a administração pública considerar sua função atender à sociedade como um todo, suas ações públicas estarão voltadas para a construção de direitos sociais e à formação do cidadão, se educação for compreendida como uma política pública social de responsabilidade do Estado, que necessita ser pensada, por sua vez, dentro de um projeto político e de uma teoria social para a sociedade. Como considera Höfling (2001), o processo de definição de políticas públicas para uma sociedade reflete os conflitos de

${ }^{8}$ A Constituição Federal Brasileira (BRASIL, 1988) no seu Título I - Dos Princípios sobre os objetivos fundamentais de uma sociedade livre, justa, solidária, com a redução das desigualdades sociais e a erradicação da pobreza; e no Capítulo II - Dos Direitos Sociais, assegura ao cidadão direitos sociais como educação, trabalho, lazer, saúde, segurança, moradia. 
interesses, os arranjos feitos nas esferas de poder que perpassam as instituições do Estado e da sociedade como um todo. Considerando-se a sociedade brasileira, extremamente desigual e heterogênea, a política educacional é composta por ações pontuais voltadas para maior eficiência e eficácia do processo de aprendizagem, da gestão escolar e da aplicação de recursos, mas essas ações

(...) são insuficientes para caracterizar uma alteração da função política deste setor. Enquanto não se ampliar efetivamente a participação dos envolvidos nas esferas de decisão, de planejamento e de execução da política educacional, estaremos alcançando índices positivos quanto à avaliação dos resultados de programas da política educacional, mas não quanto à avaliação política da educação (HÖFLING, 2001, p. 39).

Discutir a educação no contexto das políticas educacionais no Brasil é situar a educação no cenário político nacional e apresentar os desafios que se anunciam neste campo. Um dos maiores desafios, de nossa perspectiva, é a formação de profissionais de educação e a necessidade de se analisar a educação infantil e o ensino fundamental como instâncias indissociáveis do processo de democratização da educação brasileira. Contornos variados têm sido decorrentes das propostas geradas pelas práticas sociais, da academia e das políticas públicas, traduzidos na própria concepção de currículo e de proposta pedagógica.

Lendo extensamente sobre o assunto, percebe-se que é unânime, entre os pesquisadores, a importância do ensino pré-escolar (formação inicial, para crianças de 0 a 6 anos de idade) para o sucesso/o desempenho escolar das crianças nas fases posteriores; mas também engendrar formadores é um de nossos maiores problemas no tocante às políticas educacionais em todos os níveis. Um país como o nosso, no qual a desigualdade e a injustiça social são constitutivas da história e do cotidiano, sempre há muito trabalho por fazer, muito a ensinar, inclusive sobre solidariedade, generosidade e justiça social, respeito às diferenças e atuação contra a discriminação e a dominação; afinal, precisamos levar em conta diferenças étnicas, religiosas, regionais, experiências culturais, tradições e costumes de grupos diversos no seu meio de origem e no seu cotidiano de relações. Assim, favorecer às crianças experiências de cultura, com brinquedos, museus, cinema, teatro e literatura, parece-nos fundamental.

\section{CONSIDERAÇÕES FINAIS}

Inúmeras transformações ocorridas nos últimos anos no plano socioeconômico-cultural, decorrentes do processo de globalização, incidem nas dinâmicas e estruturas familiares, provocam modificações em seu padrões tradicionais de organização e compõem o cenário das políticas públicas vigentes que para serem efetivas devem contemplar a diversidade de relações que convivem na sociedade brasileira e considerar as famílias como grupos sociais compostos de indivíduos que se relacionam cotidianamente numa complexa trama. 
$\mathrm{Na}$ reunião de fechamento (comumente chamada confraternização) dos trabalhos (com a participação de familiares, crianças e equipe completa do CCazinho), em 2013, em que vimos o documentário sobre "o corpo humano em movimento" feito pelas crianças a partir de (resultado do trabalho anual da equipe do CCazinho com o grupo de crianças) pesquisas feitas nas escolas, nas residências, internet, livros e visitas do grupo à exposição, as crianças e os familiares mantiveram-se em profundo silêncio e apenas uma criança manifestou-se brevemente. Na maior parte do tempo, após a apresentação do documentário, a equipe do CCazinho tentou dialogar. Mas entrar na linguagem parecia ter uma dimensão mítica inacessível às crianças e aos seus familiares.

\section{REFERÊNCIAS}

AGAMBEN, G. Infância e História: destruição da experiência e origem da história. Trad. Henrique Burico. Belo Horizonte: 1978/2005.

BRASIL. Constituição (1988). Constituição da República Federativa do Brasil. 25. ed. Brasília: Câmara dos Deputados, Coordenação de Publicações, 2005. (Série textos básicos, n. 37).

BRUNER, J. Atos de Significação. Trad. por Sandra Costa. Porto Alegre: Artes Médicas, 1997. p. 130.

CARVAlho, M. E. P. Modos de educação, gênero e relações escola-família. Cad. Pesqui. [online]. 2004, vol.34, n.121, pp. 41-58. ISSN 0100-1574. In: http://www.scielo.br/scielo. php?script=sci_pdf\&pid=S0100-15742004000100003\&lng=en\&nrm=iso\&tlng=pt. Acesso em 3 de agosto de 2016.

COUDRY, M. I. H. Diário de Narciso. Discurso e afasia: análise discursiva de interlocuções com afásicos. Tese de doutorado, UNICAMP. 1986.

FRANCHI, C. "Linguagem - atividade constitutiva". In: Almanaque 5. São Paulo: Brasiliense. 1977.

FRANCHI, C. "Criatividade e gramática". In: Trabalhos em Linguística Aplicada. Campinas, v. 9. 1987.

FREIRE, P. A Pedagogia da Autonomia: saberes necessários à prática educativa. $21^{\text {a }}$ ed. São Paulo: Paz e Terra, 1996.

HÖFLING, E. de M. Estado e políticas (Públicas) Sociais. Cadernos Cedes, ano XXI, n ${ }^{\circ}$ 55, novembro/2001.

LEONTIEV, A. N. Uma contribuição à teoria do desenvolvimento da psique infantil. In: VIGOTSKI, L. S.; LURIA, A. R.; LEONTIEV, A. N. Linguagem, desenvolvimento e aprendizagem. Trad. Maria Penha Villalobos. São Paulo: Ícone, EDUSP, 1988. pp. 59-83.

LURIA, A. A psicologia experimental e o desenvolvimento infantil. In: VIGOTSKI, L. S.; LURIA, A. R.; LEONTIEV, A. N. Linguagem, desenvolvimento e aprendizagem. Trad. Maria Penha Villalobos. São Paulo: Ícone, EDUSP, 1988. pp. 85-102.

MARTINS, L. M.; FRANÇA, A. P. D.; KIMURA, M. Qualidade de vida de pessoas com doença crônica. Rev. Latino-am. enfermagem, Ribeirão Preto, v. 4, n. 3, pp. 5-18, dez. 1996.

MENEZES-FILHO, N. Os determinantes do desempenho escolar do Brasil. Instituto Futuro Brasil, Ibmec-SP e FEA-USP. In: http://www.cepe.ecn.br/seminarioiv/download/menezes_filho.pdf. Acesso em 19 de out. de 2016. 
QUINTANA, A. M.; ARPINI, D. M.; PEREIRA, C. R. R.; SANTOS, M. S. A vivência hospitalar no olhar da criança internada. Ciência, Cuidado e Saúde, v. 6, n. 4, pp. 414-423, out./dez. 2007.

TOURAINE, A. Critica da Modernidade. Petrópolis: Vozes, 1994.

VYGOTSKY, L. S. (1926). Psicologia Pedagógica. São Paulo: Martins Fontes, 2004.

VYGOTSKY, L. S. A formação social da mente. São Paulo: Martins Fontes, 1987.

VYGOTSKY, L. S. (1934). Pensamento e Linguagem. Trad. por M. Resende. 42a ed., Lisboa: Antídoto, 1979. 